\title{
Evolução das Técnicas de Planejamento no Brasil
}

\author{
Francisco das Chagas Melo
}

\section{$\mathrm{P}$}

LANIFICAÇÃo não é um privilégio dos regimes de fôrça, nem uma arma em mãos dos governos apontada contra a coletividade ou a iniciativa privada. Planejamento é um método, um processo, um ponto-de-vista, uma atitude.

Nesta fase decisiva da história da humanidade, todos os países ingressaram na era do planejamento, dissociando a idéia de planificação do conceito de país socialista ou socializante.

O planejamento da ação do Estado não é, pois, de inspiração totalitária. Antecipou se a ela. Surgiu dos debates dos modernos Estados-Maiores Militares e dos laboratórios de pesquisas e estudos da "grande Emprêsa" em continuo processo de integração e racionalização. Adquiriu nitidez e claridade após as severas lições da guerra, que teriam de influir poderosamente sôbre a conduta de todos os povos, ainda sôbre a dos mais apegados aos princípios democráticos. É o que persuasivamente demonstraram Paul de Vinat (Scientific Management in Europe, 1927, págs. 27 e 28) e Charles Roy (La Formulation Allemande de Production Rationnelle dans l'Industrie, pág. 8).

Como vimos, mesmo antes da Segunda Guerra Mundial já o conceito de planejamento havia sido incorporado à administração, seja na esfera pública, seja na esfera privada.

A técnica de planificação dos objetivos governamentais, no Brasil, sòmente começou a ser empregada depois da Segunda Guerra Mundial, embora antes, ou seja, em 1939, tenhamos executado o nosso Primeiro Plano Qüinqüenal, que era mais um programa de realizações em poucos setores da economia nacional do que mesmo uma previsão para o desenvolvimento.

O atraso do nosso país, em matéria de programação de investimentos, era tão grande que sòmente a Constituição de 1967 admitiu a existência de um orçamento purianual de investimentos nos têrmos do inciso III do art. 46, assim redigido: Ao Congresso 
Nacional, com a sanção do Presidente da República, cabe dispor mediante lei, sôbre planos e programas nacionais, regionais e orçamentos plurianuais.

Outros dispositivos constitucionais disciplinam a matéria:

Art. 63, parágrafo único. As despesas de capital obedecerão ainda a orçamentos plurianuais de investimentos, na forma prevista em lei complementar.

Art. 65, parágrafo 49 Nenhum projeto, programa, obra ou despesa, cuja execução se prolongue além de um exercício financeiro, poderá ter verba consignada no orçamento anual, nem ser iniciado ou contratado, sem prévia inclusão no orçamento purianual de investimento, ou sem prévia lei que o autorize e fixe o montante das verbas que anualmente constarão do orçamento, durante todo o prazo de sua execução.

A Lei Complementar $n^{9} 9$, de 7 de dezembro de 1967, que dispõe sôbre os orçamentos Plurianuais de Investimentos, define Plano Nacional o conjunto de decisões harmônicas destinadas a alcançar, no periodo fixado, determinado estágio de desenvolvimento econômico e social e será apresentado sob a forma de diretrizes gerais e dêle constarão as definições básicas adotadas, os elementos de informação que as justificarem e a determinação dos objetivos globais previstos.

Em decorrência do Plano Nacional, os projetos a serem executados, sob a responsabilidade do Poder Público, serão ordenados em programas setoriais e regionais, cuja expressão financeira é o Orçamento Plurianual de Investimento, que abrangerá periodo de três anos e será elaborado sob a forma de orçamento-programa e conterâ:

I - os programas setoriais, seus subprogramas e projetos e o respectivo custo, especificados os recursos anualmente destinados à sua execução:

II - os programas setoriais determinarão os objetivos a ser atingidos em sua execução.

O Otçamento Plurianual de Investimento indicará os recursos orçamentários e extra-orçamentários necessários à realização dos programas, subprogramas e projetos, inclusive os financiamentos contratados ou previstos, de origem interna ou externa.

O Poder Executivo, através de proposição devidamente justificada e acompanhada de relatório sôbre a fase executada, poderá, anualmente, solicitar ao Congresso Nacional seja reajustado o Orçamento Plurianual de Investimento, compreendendo:

a) inclusão de novos projetos;

b) alteração dos existentes; 
c) exclusão dos não iniciados, comprovadamente inoportunos ou inconvenientes; $e$

d) retificação dos valôres das despesas previstas.

A Lei Complementar n 3 , de 7 de dezembro de 1967, contém dispositivos altamente democráticos, conciliando a unidade do planejamento com a possibilidade de o Congresso examinar a politica geral econômica do Govêrno ou seja o mérito dos objetivos selecionados, sua compatibilidade e adequação com os objetivos do Plano Nacional, o mérito das prioridades fixadas e a previsão dos recursos indicados para atender às despesas de capital (art. 12 da citada Lei).

Para o triên'o 1968-1970 foi aprovado pela Lei $\mathrm{n}^{\circ}$ 5.450, de 5 de junho de 1968, um Plano trienal do valor global de $\mathrm{NCr} \$ 17.567 .247 .774$, distribuído pelos seguintes setores: aqropecuária, assistência e previdência, colonização e reforma agrária, comércio, defesa e segurança, educação, energia, habitação, in dustrialização, política exterior, recursos naturais, saúde e saneamento, transportes, e programas a cargo dos Estaḍos, Distrito Federal e Municípios.

A partir de 1971 teremos, em execução, não um Plano trienal e sim qüinqüenal, que deverá ser enviado ao Poder Legislativo até $1^{\circ}$ de março de 1969 e votado no prazo de 120 dias, sob pena de ser considerado aprovado.

Há, ainda, uma forte reação, mesmo nos setores politicos, contra a existência de orçamento a lonqo prazo, contrariando um dos principios clássicos da ciência das finanças que é o da anualidade orçamentária.

Diz conhecido autor que a base racional para o temor de que o planejamento econômico em geral possa ameaçar as instituicões democrāticas inclui: a) associação de planejamento econômico com totalitarismo; $b$ ) arqumentos históricos, que liqam o aparecimento do sistema de mercado competitivo com o aparecimento de instituicões livres; c) arqumentos analíticos tendentes a mostrar uma conexão entre o sistema de mercado competitivo $e$ as instituições liberais.

É verdade, continua o referido autor, que a União Soviética, Alemanha, Itália e Japão (antes da Segunda Guerra Mundial) tiveram um alto grau de planejamento econômico associado a um baixo grau daquilo a que chamamos instituições liberais. É devido ao seu planejamento econômico que as instituições naqueles países estiveram em crise? Na maioria dêsses países, as instituições liberais nunca foram estabelecidas sòlidamente: assim. é impossivel afirmar que nestes casos o planejamento econômico destruiı as instituicões livres. Além do mais, o colapso destas instituições, como êles as tiveram, foi associado com as instabilidades 
econômicas de âmbito universal, com a preparação bélica e com a guerra.

$\AA$ intensidade relativamente grande de planejamento econômico dos citados países, seguiu, ou pelo menos não precedeu, o desenvolvimento da ditadura. Em vez de concluir que planejamento econômico tende a causar a ditadura, parece mais razoável concluir que tanto a ditadura política como certos tipos de planejamento econômico poderão surgir do mesmo conjunto de causas - Planejamento econômico e instituições livres - Eugene Staley - Revista do Serviço Público - Dezembro de 1946.

Um dos exemplos mais significativos, do ponto-de-vista da adequabilidade do planejamento econômico ao regime da livre emprêsa, tem sido dado pela França, que desde o fim da Segunda Guerra Nundial já executou cinco planos qüinqüenais.

O plano francês não é imperativo e detalhado como os planos dos paises socialistas. Ele é oficialmente definido como um instrumento de orientação da economia e, no setor público, um programa de investimentos, visando assegurar a coordenação da política econômica e financeira do Estado, com os setores da economia privada.

O planejamento francês é uma fórmula original e flexível para a previsão e orientação dos setores público e privado da economia nacional.

A superação do subdesenvolvimento é uma tarefa penosa e difícil em que estão empenhados, não sòmente os próprios interessados, como também os países desenvolvidos sob a orienta. ção da "Organização das Nações Unidas."

O conhecido economista francês Claude Levy, em "Critères du Sous développement", propõe o emprêgo de onze testes principais para a aval ação do grau de subdesenvolvimento: a) mortalidade infantil; b) fecundidade do casamento; c) falta de higiene rudimentar; d) subalimentação; e) baixo consumo de energia elés trica; f) indice elevado de analfabetos; $g$ ) baixa produtividade acrícola; $g$ ) baixo nivel médio de vida; $h$ ) emprêgo de mão-deobra infantil; $i$ ) condição inferior da mulher; $j$ ) fraqueza da classe média.

O conceito de país subdesenvolvido varia, de autor a autor, e não pode ser medido por um único índice, como o de renda "per capita", que, muitas vêzes, é o resultado da acumulação de riqueza em mãos de poucos, quando a maioria permanece em condições de vida, as mais precárias.

A partir de 1960, o critério da renda "per capita", para aquilatar o subdesenvolvimento, tem sido tomado com reserva, dado o conceito atual de que desenvolvimento implica em uma melhoria geral do ponto-de-vista econômico e social da população, reser- 
vando-se a palavra crescimento econômico para o aumento da renda nacional que às vêzes se concentra em determinados setores da economia. Assim, o desenvolvimento sòmente ocorre quando - crescimento do produto nacional bruto é muito superior ao aumento do crescimento demográfico, que, no Brasil, é, aproximadamente, de $3,2 \%$ ao ano.

Tomando por base a década de 1960 , verificaremos que progredimos um pouco nos três primeiros anos, com um crescimento do produto nacional bruto de 6,7 em 1960, 7,3 em 1961, 5,4 em 1962, para regredirmos violentamente em 1963, cujo crescimento foi de 1,6, melhorando progressivamente em 1964, 1965, 1966 e 1967, com as seguintes taxas de crescimento: $3,1,3,9,4,4$, e 4,8 .

Exemplos significativos, de que a "renda per capita" significa pouco, basta citar países como a Arábia Saudita, Kuwait, Venezuela que, em virtude da exploração petrolifera, têm nivel razoável de renda "per capita" superior mesmo a do Japão, país altamente industrializado e que, entretanto, apresenta um nivel gerai de desenvolvimento econômico-social muito superior ao dos citados paises.

Assim, os objetivos do planejamento econômico são uma melhoria geral do nivel de vida da população, mais escolas, hospitais, melhor produtividade agrícola e industrial e menor depen dência do exterior na importação de produtos essenciais.

"Le but général de tout programme de développement est de stimuler le développement. Mais cela n'est pas suffisament précis. Le terme développement peut se compreendre de bien des façons différentes. Dans un programme de développement, il est indispensable de préciser quelles sont les formes de dévelop. pement envisagés. Parmi les buts tous importants en Afriques qu'un programme de développement peut envisager, on peut citer les suivants: réduire la misère et la malnutrition des masses passer d'une économie de subsistance à une économie monétaire - réalizer une plus grande diversification des exportations isoler davantage l'économie des fluctuations des marchés mondiaux - encourager les exportations - accroître da production aussi rapidement que possible - jeter les fondements du développement futur - attirer des capitaux étrangers - encourager les investissements nationaux - accroître rapidement la consomation - freiner la consomation afin de d'accroître les investissements - favoriser l'industrialisation - encourager l'agriculture, etc. On remarquera immédiatement que ces buts ne sont pas tous compatibles et qu'il peut être difficile de répartir entre eux des ressources limitées. Il importe que le aouvernement indique exactement quelles sont ses intentions. Autrement, on ne comprendra bien les politiques qu'il adopte, ni les projets qu'il envisage." Problems relatifs aux techniques de programmation du dé- 
veloppement en Affrique-Mémoire préparé par la Commission Economique pour l'Afrique (Nations-Unies) à l'occasion de la Réunion d'experts d'Addis-Abeda - 1959.

Os investimentos objetivando o combate ao subdesenvolvimento não se resume em aplicações maciças em determinados setores, como petróleo, energia, rodovias, descurando-se outros aspectos importantes da economia, como, por exemplo, a agricultura e os setores sociais da educação, saúde e saneamento.

O desenvolvimento econômico deve ser integrado, abrangendo todos os aspectos da vida econômica, para que se propague uniformemente a tôdas as camadas da população.

Como salientou com grande propriedade o eminente economista e sociólogo francês Yves Lacoste, "as causas profundas da relativa estagnação econômica dos paises subdesenvolvidos são complexas e existem numerosas teorias diferentes que tentam explicá-las. Na maioria dos casos, as dificuldades econômicas dos países do Terceiro Mundo são imputadas a causas permanentes ou eternas; como todos os paises desenvolvidos se encontram nas zonas temperadas, e como a maioria dos paises subdesenvolvidos está situada nas zonas tropicais, deduziu-se que o avanço de uns e o atraso de outros devem-se à desigualdade das condições oferecidas por êstes meios naturais muito diferentes. Alguns explicam o atraso pela ausência de climas estimulantes próprios das reqiões temperadas, onde o inverno acentuado retempera as energias humanas. Outros sublinharam os efeitos nefastos das endemias tropicais. Enfim a fraailidade e a pobreza dos solos tropicais são consideradas como um "handicap" decisivo para essas regiōes. Ora, vastas partes do Terceiro Mundo estão situadas nas zonas temneradas e elas não são menos subdesenvolvidas. Portanto, as dificullades particulares que pesam sôbre as reqiões tropicais ( $e$ que são despreziveis no auadro de uma política de desenvolvimento) não podem ser consideradas como causa profunda do subdesenvolvimentn. Yvec Lacoste - Geografia do Subdesenvolvimentn. páa. 195 - Difusora do Livfo - Universidade de São Pairlo - 1966

Nas páginas seguintes, iniciaremos o estudo das diferentes tentativas de planejamento já realizadas no Brasil, apontando as dificuldades e os erros muito naturais em um país complexo como o Rracil, onde predominam economias regionais nãn inteqradas $0: 1$ completamente estanques, dif'cultando qualquer politica de con* junto na solução dos diferentes problemas que desafiam a nossa capacidade e os nossos parcos recursos financeiros.

As dotações para obras públicas não obedeciam, no orçamento federal, a um plano prèviamente traçado, nem a uma 
hierarquia em face das necessidades coletivas ou dos grandes problemas nacionais. Os créditos eram votados por influência politica, e raros os problemas sistemàticamente atacados, como aconteceu, por questões meramente humanitárias, com as sêcas do Nordeste brasileiro.

Sòmente com o Decreto-lei n? 240, de 1938, é que foram traçadas normas gerais para construção de edifícios públicos, ficando estabelecido que nenhuma importância global poderia ser solicitada sem prévio projeto e respectivo orçamento.

Em 1939, o Decreto-lei n: 1.720 , de 30 de outubro de 1939 , atribuiu ao Departamento Admin strativo do Serviço Público a revisão dos projetos de edificios destinados aos serviços públicos civis.

Na Exposição de Motivos de que resultou o Decreto-lei número 1.720 , salientou o Departamento Administrativo do Serviço Público o seguinte:

"Não existindo um órgão apropriado centralizador ou orientador dos planos e programas de construção dos prédios para os serviços do govêrno, cada setor administrativo, por órgãos especia's ou improvisados, elabora os projetos e orçamentos e executa ou contrata os serviços, segundo a orientação pessoal dos dirigentes. Mais grave ainda, as obras, sem que qualquer motivo justifique, são feitas ora mediante concursos de projetos, concorrência pública, concorrência administrativa, ou sem concorrência, ora por empreitada, por administração e, em muitos casos, pagas mediante adiantamentos.

"Como conseqüência, o custo médio de obras iguais ou equivalentes varia de forma impressionante. Ora são projetos que não atendem às normas de parcimônia; umas vêzes, a má execução permite o encarecimento e em outras êsse encarecimento provém das elevadas quantias ou percentagens pagas aos projetistas $e$ construtores.

"Estudo procedido por êste Departamento demonstrou, claramente, a necessidade inadiável da existência de um órgão que oriente o Govêrno na solução racional da construção dos edifícios para os serviços da administração civil, fixando normas uniformes e dando orientação técnica às diversas entidades incumbidas dos projetos iniciais, nos Ministérios."

Centralirou-se, ascim, no antiqo DASP, a execução e construção de edifícios públicos, nos seguintes têrmos:

a) propor ao Presidente da República as medidas que julgar convenientes à construção, remodelação ou adaptação de edifícios destinados aos serviços públicos civis;

b) estabelecer um sistema de normas e padrões para construção dêsses edifícios; 
c) rever os projetos, orçamentos e contratos de construção, remodelação ou adaptação dos referidos edifícios;

d) fiscalizar, quando necessário, a execução dos projetos e contratos submetidos ao seu estudo.

Dependiam, pois, da autorização prévia do Presidente da $\mathrm{Re}$ pública, mediante parecer do antigo DASP, as obras que importassem em construção, remodelação, ou adaptação de edifícios, salvo as de simples conservação, que podiam ser autorizadas pelos respectivos Ministros de Estado.

Para cumprir as finalidades acima enumeradas, foi criado, pelo Decreto-lei n' 2.143, de 22 de abril de 1940, o Serviço de Obras do Departamento Admin strativo do Serviço Público.

Instalado o Serviço de Obras foram efetuados estudos obje. tivando o estabelecimento de normas para execução e construção de edifírios públicos, consubstanciadas em uma série de especificações aprovadas na Exposição de Motivos n 1.629 , de $1^{\circ}$ de outubro de 1940.

Disse a citada Exposição de Motivos que "a grande varie. dade de normas que, nesse part:cular, tem resultado da autonomia dos escritórios de obras, dificultou sensivelmente o estudo dos primeiros projetos encaminhados ao Departamento, que foi levado a admitir uma razoável marg̣em de tolerância para evitar atrasos prejudiciais no andamento dos processos."

"O acúmulo, porém, de casos a resolver, continua a Exposição de Motivos, e a necessidade de encará-los, não do ponto-devista da simples verificação de cálculos orçamentários, mas de um outro mais amplo, que é o da adequação às finalidades prè vistas, impõem o estabelecimento imediato de medidas normativas de caráter geral, suficientemente elásticas para comportarem o desenvolvimento futuro que a prática aconselhar."

Com a criação, pelo Decreto-lei $n^{\circ} 5.993$, de 16 de novembro de 1943. da Divisão de Edifícios Públicos no Departamento Administrativo do Serviço Público, e órgãos congêneres nos Ministérios civis, foi estruturado um sistema, tendo o antigo DASP, como órgão de cúpula, as seguintes atribuições:

a) estudar e sugerir os padrôes e normas para a construção dos edifícios públicos;

b) examinar os projetos, orçamentos e contratos de construção, remodelação ou adaptação dos referidos edifícios;

c) apresentar, quando fôr o caso, projetos, orçamentos e especificações de edifícios destinados à instalação de serviços pertencentes a mais de um Ministério;

d) inspecionar ou fiscalizar, sempre que julgar necessário, a execução dos projetos e contratos submetidos ao seu estudo; 
e) estudar, em colaboração com a D.E.P. e o S.S. do Ministério correspondente, os edifícios públicos, segundo o seu destino, propondo as adaptações necessárias;

f) elaborar, de acôrdo com as entidades próprias, as especificações do material de construção;

g) organizar o Código de Obras da União;

h) manter permanente contato com os serviços de obras dos Ministérios, no sentido de promover a unidade de métodos de trabalho e contrôle dos resultados;

i) manter em dia a estatística dos preços do material de construção e de custo da mão-de-obra, nas diversas zonas do pais.

O sistema de contrôle e fiscalização de edifícios públicos centralizados no DASP funcionou até 15 de março de 1967 quando o Decreto-lei $\mathrm{n}^{\circ} 200$, de 25 de fevereiro do mesmo ano, emı seu artigo 196, extinguiu a Divisão de Edifícios Públicos do DASP, transferindo o setı acervo para o Departamento de Serviços Gerais, criado no Ministério da Fazenda.

Constituem atribuições do Departamento de Serviços Gerais, no que respeita à administração de edifícios e instalações:

a) preparo de um programa geral, e seu desdobramento em etapas, para conveniente instalacão, pelos Ministérios, do programa que fôr aprovado pelo govêrno; instalações;

b) estudo de normas para administração dos edifícios e

c) elaboração de padrões de conservação e manutenção de equipamentos; $e$

d) fiscalização das medidas aprovadas.

O Decreto-lei $\mathrm{n}^{\circ} 200$ - Reforma Administrativa, em um Título Especial XII - Das normas relativas a licitações para compra, obras, servicos e al'enações, estabeleceu novas exigências para execução de obras ou serviços.

Diz o art. 132, do referido decreto-lei, que as licitações para obras ou serviços admitirão os seguintes regimes de execução:

a) empreitada por preço global;

b) cmpreitada por preço unitário;

c) administração contratada.

As obrigações decorrentes de licitação ultimada constarão de:

a) contrato bilateral, obrigatório no caso de concorrência e tacultativo nos demais casos, a critério da autoridade adminis. trativa;

b) outros documentos hábeis, tais como carta-contratos, empenho de despesa, autorizações de compra e ordens de execução de serviços. 
O grande mérito da reforma administrativa foi o de ter criado um Sistema de Serviços Gerais, tendo como órgão central normativo a Secretaria-Geral do Ministério da Fazenda, como órgãos setoriais o Departamento de Administração de cada Ministério e como órgão operacional o Departamento de Serviços Gera's do Ministério da Fazenda, além de estender às autarquias federais a observância das normas especificas da administração centralizada.

\section{II}

Como vimos, já em 1939, tínhamos um plano para o contrôle dos orçamentos e projetos de construção e reconstrução de edificios públicos, com normas uniformes ditadas por um órgão central - U Departamento Administrativo do Serviço Público - dando orientação técnica às diversas entidades incumbidas dêsse trabatho nos Ministérios e demais órgãos do serviço público federal.

Os demais setores das obras públicas - exatamente os mais importantes - como a construção de ferrovias, rodovias, obras de saneamento e a criação das chamadas indústrias básicas, continuavam sem um planejamento adequado, com soluções es^ parsas sem continuidade administrativa.

Como um primeiro esbôço de solução de conjunto, tendo $\mathrm{em}$ vista as necessidades nacionais, foi instituido, pelo Decreto-lei $\mathrm{n}$ ? 1.058, de 1939, o primeiro Plano Qüinqüenal Brasileiro Plano Especial de Obras Públicas e Aparelhamento da Defesa Nacional - com as seguintes finalidades:

a) criação de indústrias básicas;

b) execução de obras públicas;

c) aparelhamento da defesa nacional.

A execução dêsses empreendimentos com recursos próprios, sem prejuizo do equilibrio orçamentário, foi umas das preocupa. ções do esquema financeiro do Plano. Para isso, foram criadas as seguntes receitas que deveriam custear os encargos decorrentes do nosso primeiro "Plano de Obras:"

a) taxas sôbre operações cambiais;

b) lucro das operações bancárias em que o Tesouro tenha co-participação;

c) produto das cambiais provenientes de ouro metálico já adquirido e a adquirir, que exceda a $28 \mathrm{t}$ e fôr remetido para o exterior;

d) produto de qualquer operação de crédito realizada para o fim especial de que trata o decreto-lei que instituiu o Plano, inclusive a emissão de papel-moeda. 
A partir de 1939, o Govêrno Federal passou a executar as obraj públicas através da Verba Obras do orçamento ordinário e do nôvo orçamento paralelo.

Os investimentos do Plano Especial atingiam, segundo as estimativas, $\operatorname{Cr} \$ 600.00,00$ anuais, quantia essa coberta em cêrca de $50 \%$ pela emissão de papel-moeda, já que as fontes de renda especiais criadas foram insuficientes para cobrir a previsão.

O Plano foi instituído, como o seu nome indica, para atender não só às obras públicas, como também aos empreendimentos que visassem ao aparelhamento da defesa nacional, instalação e exploração de indústrias básicas.

No setor de obras públicas, no sentido geral de obras de qualquer natureza sem uma escala prioritária, passamos a ter duas fontes de execução: a do Plano e da verba "Obras" do Orçumento Ordinário. Como não havia um programa prévio de obras aprovado, as verbas do Plano passaram a reforçar as dotações da verba "Obras" do orçamento ordinário, impossibilitando qualquer contrôle por parte do govêrno das obras que estavam sendo executadas.

No setor do aparelhamento da defesa nacional, em face do inicio da Segunda Guerra Mundial, pode-se depreender que, em grande parte, a intenção visada foi satisfeita, porque o total de créditos anualmente distribuido para êsse fim correspondeu, aproximadamente, a $64 \%$ dos recursos do Plano, conforme salientou - govêrno através do Ministério da Fazenda, em Exposição de Motivos ao Presidente da República, da extinta Comissão de Orçamento, de 13 de dezembro de 1943.

Examinando o conceito de indústria básica para analisarmos o que foi feito neste setor, verificaremos que a ação do "Plano" foi completamente nula.

Por indústria básica, na época, pois que o conceito varia no tempo e de país a país, entenderemos os seguintes ramos industriais:

a) indústrias metalúrgicas em geral, compreendendo as siderúrgicas, e produção de metais não-ferrosos:

b) indústrias quimicas;

c) indústrias mecânicas;

d) transportes ferroviários, rodoviários, fluviais e marítimos;

e) produção de energia elétrica:

f) petróleo;

g) produção de materiais de construção civil.

No período de vigência do Plano, de 1939 a 1943, quase nada foi feito nos setores acima indicados, à exceção de dois empreendimentos que não foram executados com recursos do nosso primeiro Plano Qüinqüenal: a criação do Conselho Nacional do Petróleo e os primeiros estudos de prospecção do referido produto 
e os levantamentos consubstanciados no Relatório da Comissão Executiva do Plano Siderúrgico Nacional, que resultou na fundação da Companhia Siderúrgica Nacional.

Assim, do nosso primeiro Plano Qüinqüenal, salvou-se apenas o nome e a idéia da necessidade de planejamento, que iria refletir -se na elaboração do nosso segundo Plano.

Com o término, em 1943, do mencionado Plano, compreendeu o govêrno a necessidade de corrigir o defeito da existência de dois orçamentos para a execução de obras públicas, e de aproveitar a experiência conseguida com a instituição de um regime especial para sua execução.

"Verificada a necessidade de instituir um nôvo Plano de Obras, em prosseguimento ao antigo Plano Especial, que vigoraria até 31 de dezembro de 1943 , a Comissão de Orçamento foi incumbida dos estudos pertinentes a sua elaboração. Suas investigações e análises levaram-na, preliminarmente, à conclusão de que deveriam ser eliminados os inconvenientes da ocorrência de dois grupos de obras públicas financiadas separadamente - 0 da Verba Obras do orçamento ordinário e do antigo Plano Es. pecial. Tornava se necessário reuní-los. A reunião dos dois grupos criou o dilema - trazer as obras do Plano em extinção para o campo do orçamento ordinário, inscrevendo-as na Verba Obras, ou retirar dêsse orçamento essa Verba e fundi-la num Plano que substituísse o que se extinguia. Optou-se pela segunda hipótese, isto é, pela reunião de tôdas as obras públicas em um só Plano Nacional, executado paralelamente ao orçamento ordinário" Proposta Orçamentária para 1944 - Relatório - Imprensa $\mathrm{Na}$. cional, página 370 .

Compreendeu a atinga Comissão de Orçamento do Ministério da Fazenda que os inconvenientes mais comumente apontados na execução das obras públicas eram a falta de planejamento geral capaz de interrelacionar as necessidades públicas que as várias obras e construções visam satisfazer, e as dificuldades surgidas no emprêgo, em tempo útil das dotações, resultando retardamento e interrupção das construções autorizadas.

A eliminação dêsses inconvenientes dependia da implantação de regras novas na execução de obras públicas, como sejam: a) a realização de qualquer obra pública deveria ser posta em função do problema geral que ela integra, isto é, um Plano, uma visão geza! das necessidades do país; e $b$ ) a execução do orçamento da obra por projeto e não por exercício, o que equivale a dizer, uma ve $z$ aprovado pela autoridade competente, deve-se ter como estabelecido que os orçamentos dos exercícios segtintes serão automàticamente onerados das quantias que o projeto prevê para
cada ano. 
Ao analisar a conjuntura da execução de obras públicas no Brasil, estabeleceu a antiga Comissão de Orçamento do Ministério da Fazenda, em 1943, as seguintes idéias básicas:-a) a necessidade de um só plano para as obras públicas; $b$ ) a substituição do atual regime orçamentário por um outro adequado à presente fase de evolução do serviço público brasileiro; e c) a atrıbuição a um órgão central de planejamento, dependente de estudos posteriores, de competência para elaborar o Plano, velar pela sua realização e atender às alterações que se tornarem necessárias.

Justificando essas idéias, salientou o antigo presidente da Comissão de Orçamento, Dr. Luiz Simões Lopes, em sugestóes apresentadas em 13 de dezembro de 1943, ao Senhor Ministro da Fazenda o seguinte: $1^{\circ}$ ) planificar um setor da economia privada significa estabelecer domínio sôbre as fôrças cegas dessa economia, em que não se interfere eficazmente sem algo cortar da iniciativa individual e da livre concorrência. Mas, a Adminis، tração Pública exclui, por sua natureza, a existência dêstes dois atributos. Tôdas as atividades do Estado visam fins gerais, Quando êle intervém, é para regular a procura ou impedir os males da concorrência livre. Se seus fins são gerais no espaço e no tempo, sem subordinação ao lucro e ao êxito imediato, suas atividades são, por natureza, atividades globais, genéricas e coletivas, que forçosamente devem obedecer a plano prèviamente concebido; $2^{\circ}$ ) para sistematizar a aplicação dos capitais de que o govêrno dispónha, é imprescindivel trabalhar com tôdas as va. riáreis suscetiveis de observação científica, tendo em vista tôdas as fôrças que definem o sentido do desenvolvimento econômico e social. Êste desenvolvimento é agora conduzido por influências que anteriormente não o antingiam. Vamos entrar na fase da industrialização, fase mais viva e mais difícil de dirigir que a açropecuária; $3^{\circ}$ ) o país entra em fase de desenvolvimento econômico caracterizada por fôrças mais vigorosas e de resultados mais complexos. Dai a necessidade de planejamento geral que possibilite trabalho de maior precisão; $4^{\circ}$ ) os órgãos de planejamento devem estabelecer um contato permanente com os órgãos de previsão orçamentária, de modo a poderem acompanhar a vida econômica do pais e conhecer o desenvolvimento das fontes de recursos; $5^{\circ}$ ) a separação da execução, num mesmo instrumento, das despesas civis, das obras para defesa nacional, visto que as obras de defesa não têm como objetivo imediato o fim econômico social que caracteriza as demais obras; 6\%) a elaboração dos projetos militares é enfeixada em órgãos específicos de defesa, não sòmente por motivos de especializacão, mas também pela necessidade de siailo. Esta última condição exige dos técnicos militares conhecimentos mais amplos que os exigidos para as obras civis. A necessidade do sigilo dificulta a audiência de especia- 
listas de quadros estranhos aos órgãos de defesa. Mas, para compensar essas dificuldades, os técnicos militares contam com a aceitarão espontânea dos métodos racionais de planejamento. Isto, principalmente, porque a defesa armada sempre foi, e será, um serviço público de reconhecida necessidade que não recebe nem tolera especìficamente a oposição de interêsses pessoais. Os grupos nacionais de interêsse econômico nunca se upõem a que - Estado fortifique qualquer ponto do território nacional, sem fazer pressão para que uma fortaleza seja construída em determinada região. Entretanto, interferem na construção de portos, açudes e estradas; 7\%) a liberdade de movimentos de que dispõe - Estado para a realização de obras militares está condicionada aos recursos tinanceiros e à concepção que tenham os governantes dos riscos a que a Nação se ache exposta; 8 !) a Constituição revela êsse senso de plano na organização da defesa, quando, no artigo 162, entrega o estudo de tôdas as questões relativas à defesa do pais a um só órgão, o Conselho de Segurança Nacional; 9ः) justifica-se plenamente a não reunião das obras militares e das obras civis em um só plano. Com base nas diretrizes acima indicadas, a antiga Comissão
de Orçamento do Ministério da Fazenda elaborou um nôvo Plano Qüinqüenal para vigorar de 1944 a 1949.

O esquema de distribuição do Plano proposto foi o seguinte: a) as receitas do Plano anterior foram transferidas ao nôvo Plano de Obras e Equipamentos; $b$ ) as despesas para obras que constituíam a Verba 5 - Obras do Orçamento Geral da União e respectivas receitas foram transferidas para o nôvo "Plano" e ali discriminadas de acôrdo com os projetos e programas prèviamente aprovados; e c) as despesas militares de aquisição de material bélico e aparelhamento da defesa nacional passaram á ser custeadas por créditos extraordinários. Salientou a exposição do presidente da antiga Comissão
de Orçamento ao Senhor Ministro da Fazenda que "no sistema proposto, procura-se um têrmo de equilibrio entre os pontos-devista, até agora em choque, na apreciação do regime apropriado às obras públicas. Ante os argumentos favoráveis à manutenção põe-se, para a concessão, o processo de discriminação prévia em tabelas com uma reserva para distribuição "a posteriori". Mantém-se o regime existente de contrôle, dependente das alteraçôes que estudos ulteriores venham a aconselhar."

Por outro lado, é preciso notar que, no defender-se a antiga tese da inclusão das obras do Plano Especial na verba "Obras" do orçamento ordinário, não se pretendia sòmente submeter tôdas vista principalmente evitar os inconvenientes de dois programas 
que não se ajustavam convenientemente. De fato, a técnica de planejamento era desvirtuada pela ocorrência de dois blocos de receitas correspondendo cada uma a um conjunto de projetos e programas de obras."

"A reunião de tôdas as obras, em um só Plano, afastam em ćefinitivo os inconvenientes diversas vêzes apontado. Buscando - equilibrio dos pontos de-vista referidos, talvez não se tenha ateridido, quanto necessário e mediante o sistema proposto, à mobilidade dos projetos econômicos. Todavia, um notável progresso já caracteriza a satisfação dos designios procurados". Inicia-se nova etapa em que a experiência até agora adquirida é largamente aproveitada, sem prejuizo de novas formas que es. tudos posteriores venham a indicar."

A dualidade de orcamento vigorante, um orçamento ordinário e outro paralelo, dificultou o contrôle da execução e incentivou a proliferação de obras novas sem estudos prévios, que mais tarde foram paralisadas ou tiveram o seu prosseguimento através do orçamento comum.

Como bem salientou o engenheiro Liberato Soares Pinto, "o Plano Especial, por sua maior plasticidade quanto ao aspecto contábil, representou apenas uma válvula de segurança utilizada pelos Ministérios como fonte complementar de recursos, criando mesmo, justamente pela maior facilidade de aplicação, uma sobrecarga de compromissos crescentes de ano a ano. Com efeito, é fácil compreender que nos casos de obras em prosseguimento, as formalidades a preencher para a inclusão de recursos no orçamento ordinário eram bastante mais simples do que aos das obras novas. Nessas condições, iniciavam-se as obras públicas pelo Plano e custeava-se o seu prossequimento pela Verba Obras - Planejamento de Obras - Revista do Serviço Público Dezembro de 1946, pág. 129.

\section{III}

Com as justificações acima apontadas, foi criado, pelo Decreto-lei $n^{\circ}$ 6.144, de 29 de dezembro de 1943 - o Plano de Obras e Equipamentos para vigorar a partir de $1^{\circ}$ de janeiro de 1944, na ordem histórica, a segunda tentativa de planejamento no Brasil.

A execucão total do Plano foi estimada em cinco bilhões de cruzeiros antigos, anualmente aplicável, pela quinta parte, sob a forma de orçamento especial.

A recelta do Plano era constituída dos seguintes recursos:

a) Taxa sôbre operações cambiais. 
b) Lucro das operações bancárias em que o Tesouro tenha co-participação. o exterior.

c) Produto de cambiais provenientes de ouro remetido para

d) Juros das contas especiais, abertas no Banco do Brasil para centralização dos recursos previstos neste decreto-lei e das contas do Plano a que se refere o Decreto-lei $n^{\circ} 1.058$, de 19 de janeiro de 1939.

e) Dividendos de capitais da União empregados em socie. dades de economia mista ou autarquias de exploração comercial ou industrial.

f). Produto de operações de crédito.

g) Saldos que forem apurados nos balanços gerais da Receita e Despesa da Uniâo.

h) Outras rendas que eventualmente the forem atribuidas.

Os recursos do Plano eram arrecadados pelo Ministério da Fazenda e centralizados em conta especial no Banco do Brasil e movimentada exclusivamente pelo Ministro da Fazenda, na conformidade das instruções expedidas pelo Presidente da República, que determinará, anualmente, a aplicação dêsses recursos pelos diversos Ministérios e demais órgãos da administração, destinando-os à execução de obras públicas e equipamentos.

A realização das despesas obedecerá às tabelas discriminativas, organizadas pela extinta Comissão de Orçamento do Ministério da Fazenda e anexas ao decreto-lei que expedir o orçamento especial e de acôrdo com os destaques que, no decorrer do exercício, forem prèviamente aprovados pelo Presidente da República.

A comprovação das despesas realizadas para execução do "Plano" eram feitas perante os Ministros de Estado e dirigentes dos órgãos subordinados ao Presidente da República.

Examinadas e julgadas as contas por estas autoridades, era feito um circunstanciado relatório ao Ministro da Fazenda, que o submeteria ao Presidente da República com um demonstrativo da Contadoria-Geral da República sôbre as operações de receita e despesa, para final apreciação por parte do Tribunal de Contas.

O regime de execução de despesas do "Plano" procurava relacionar determinados problemas nacionais e executá-los imediatamente, dada a isenção de registro prévio de despesas, dando ao govêrno inteira liberdade de aplicação das mesmas.

Essa coordenação de atividades procurou-se dar ênfase no nốvo Plano, não sòmente nas obras do govêrno federal, como do govêrno estadual.

A titulo de exemplo, disse a Exposição de Motivos de que resultou o "Plano", ê oportuno relacionar um grupo de problemas técnicos considerados por estudiosos e especialistas como proble- 
mas nacionais. São "slogans" que surgem freqüentemente na imprensa e em livros bem intencionados. Cada escritor ou articulista apresenta o seu problema como nacional. Eis alguns exemplos: a) aproveitamento do Rio São Francisco; b) sanea. mento da Amazônia; c) povoamento do Brasil-Central; d) ligação terrestre do Centro-Sul com o Nordeste e com o Norte; e) ligação Bahia-Piauí-Maranhão; f) ligação Rio-Bahia; $g$ ) trecho Ipameri-Belèm (rodovia transbrasiliana); $h$ ) ferrovia BrasilBolivia: i) estrada Brasil-Paraguai; j) eletrificação rural."

Não parece que a qualquer dêsses empreedimentos se possa chamar de nacional, no sentido de chave ou de único meio de salvação. Nenhum dêles pode ser estudado ou executado isoladamente. São nacionais porque interessam à Nação, mas são interdependentes. Embora sem planejamento geral, o Govêrno da União tem tratado de quase todos êles.

A necessidade do estudo de conjunto vai muitas vêzes além da esfera federal, como se pode verificar mediante alguns exemplos. Veja-se de início a zona caucaueira do sul da Bahia. A economia regional dêsse produto é orientada pelo Instituto do Cacau, autarquia do Govêrno estadual da Bahia. Atendendo aos mais louváveis intuitos, aquêle órgão estadual da Bahia empreendeu melhoramentos na área cacaueira, que tem como centro econômico os ricos municipios de Ilhéus e de Itabuna. Melhoraram-se estradas e portos, tendo em vista amparar essa região agricola. Ocorre, porém, que o cacau não é um produto essencial. $\hat{\mathrm{E}}$ tìpicamente um produto de exportação, e conquanto nos caiba aproveitar qualquer fonte de produção, não se examinou em tempo se a conjuntura econômica brasileira indicava, na ocasião, a inversão de capitais em outros empreendimentos.

Outro exemplo é o da baixada do litoral paulista. Enquanto a industrialização se processa no planalto, essa região se conserva como pitorescamente a denominou um escritor - uma planície de bananeiras e mangues. Outro caso idêntico é o do norte do Paraná, onde se pratica a colonização pela iniciativa privada, sem nenhum incentivo por parte do govêrno.

Os três exemplos - baixada paulista, povoamento do norte do Paraná e obras da região cacaueira - mostram a falta de coordenação, isto é, a falta de um plano nacional a que as obras se relacionem e de que dependam. O aproveitamento da baixada paulista ainda não surgiu como problema nacional. Mas não poderá ser deixado apenas a cargo do govêrno estadual. A economia do cacau é orientada pelo govêrno baiano. A penetração São Paulo-norte do Paraná interessa a dois Estados e se realiza em zona estratégica onde há imigração e capitais estrangeiros.

Nenhum dos três problemas figura, entretanto, vultosamente como o das sêcas do Nordeste, nos orçamentos federais, nem no 
ordirário, nem no Plano Especial. Mas, tanto êles como as sêcas, - Rio São Francisco, o saneamento da Amazônia e os demais problemas abertos devem ser subordinados à conjuntura econômica do país que, por sua vez, é função da economia mundial. Êstes são os crivos a que obrigatòriamente devem ser submetidos todos os planos regionais. São êles que devem inspirar a politica de inversão de capitais em obras públicas, e que devem determinar quais as obras e trabalhos a executar, como, onde e quando devem ser executados em plano nacional.

Segundo o Relatório da antiga Comissão de Orçamento do Ministério da Fazenda - Imprensa Nacional - 1944, páginas 372 e seguintes, as vantagens do nôvo Plano de Obras estão assim sintetizadas:

a) as obras públicas por êle custeadas gozam de regime contábil uniforme e mais compativel com as despesas dêsse gênero do que o aplicado às demais despesas da administração;

b) as obras públicas ficam enquadradas em regime contábil e especial até que estudos posteriores indiquem regime próprio e definitivo;

c) evita-se que o falso respeito à anualidade orçamentária, como freqüentemente acontece, facilite a execução de obras públicas pelo regime de adiantamentos:

d) como as obras públicas constituem inversões de capital, que materialmente enriquecem o patrimônio, e muitas delas são de caráter produtivo, sua realização pode, em parte, ser custeada por meio de operações de crédito, quando a receita ordinária não fôt bastante para seu financiamento;

e) a exclusão das obras públicas do Orçamento Geral proporcionaria um razoável e imediato equilibrio entre as rendas normais e as despesas de custeio da administração do Estado;

f) tornar-se-ia possivel a elaboração de um só plano nacional para as obras federais, em vez de planos parciais e dispersos.

O Plano de Obras e Equipamento pode ser considerado como a primeira tentativa séria de planejamento do setor público de investimentos, uma vez que nenhuma diretiva foi traçada ao setor privado.

Admitiram-se, pela primeira vez, duas idéias básicas do planejamento moderno: o princípio de que a realização de qualquer obra pública é posta em função do problema geral que ela integra, e a sua execução deve fugir ao critério falho de créditos anuais, sujeito a exame e discussão, quando o correto seria a inclusão automática no orçamento de parcelas prèviamente aprovadas.

Se o Plano foi perfeito quanto ao aspecto contábil e de financiamento, fracassou na formulação das obras a serem construídas, que continuaram a ser executadas, por fôrça do Decreto-lei nú- 
mero 6.145, de 29 de dezembro de 1943, dentro dos Ministérios, adotando-se o sistema falho de obras por exercícios e não por projetos.

Assim, pelo Decreto-lei acima citado, de $\mathrm{n}^{2} 6.145$, de 29 de dezembro de 1943, foi fixada a despesa do primeiro ano de funcionamento do nôvo Plano, distribuída da seguinte forma:

1 - Departamento Ad. do Serviço Público ..........

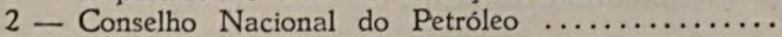

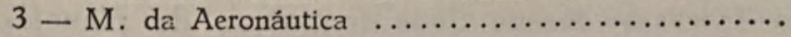

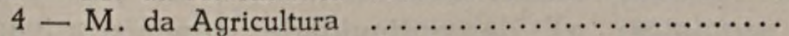

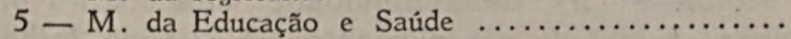

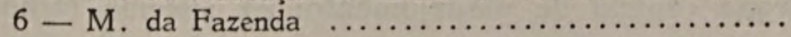

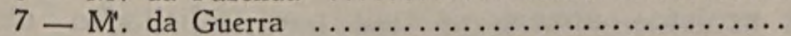

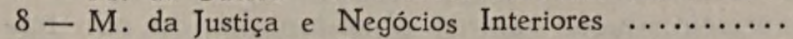

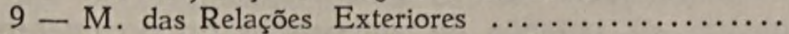

10 - M. do Trabalho, Indústria e Comércio ..........

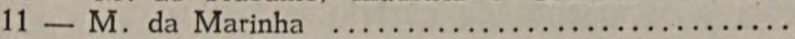

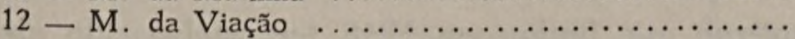

Soma $\ldots \ldots \ldots \ldots \ldots \ldots \ldots \ldots \ldots \ldots$

No primeiro ano de funcionamento do segundo Plano, nenhum assunto mencionado na Exposição de Motivos de que resultoti o primeiro Orçamento Especial foi tratado, nem tampouco relacionado à conjuntura econômica do País. Foi feita, apenas, uma literatura econômica que iria predominar na feitura dos $\mathrm{Pla}$ nos subseqüentes, dissociando-se o planejamento escrito, de sua execução pròpriamente dita. As verbas foram gastas dispersamente, em várias obras públicas, sem resolver nenhum daqueles problemas relacionados como urgentes ou prioritários.

Com o advento de um nôvo govêrno em 1946, foi o Plano de Obras e Equipamentos extinto pelo Decreto-lei $\mathrm{n}^{\circ}$ 9.782, de 6 de dezembro de 1946, sob dois fundamentos principais: a) precária situação das finanças públicas e $b$ ) proibição de orçamentos paralelos por parte da Constituição de 1946.

O primeiro argumento peca pela base, pois os reduzidos déficits orçamentários de 1945 e 1946 e um superavit em 1947, demonstram que não era de penúria a situação das finanças públicas.

Com a extinção do Plano de Obras, o govêrno reduziu nos anos de 1946 e 1947 as despesas de investimentos a menos de $10 \%$ da despesa global do País.

Um fenômeno interessante e talvez peculiar à economia brasileira é o fato inusitado de que, em 1948, sem nenhum Plano em execução, e com uma taxa de investimentos públicos de menos de $10 \%$ do orçamento federal, o País cresceu em 1948, cêrca de 
9,5 em seu produto interno bruto, conforme dados do Instituto Brasileiro de Economia da Fundação Getúlio Vargas, e 6,2 na renda per capita, como esclarece a mesma fonte, o que demonstra ser a iniciativa privada a responsável por êsse notável crescimento, jamais atingido nos últimos vinte anos, apesar de o govêrno federal ter investido uma média de $40 \%$ do orçamento total, que por sua vez representa $30 \%$ do total da renda nacional.

Com a extinção do Plano as suas dotações incorporaram-se na Verba Obras do orçamento ordinário.

As caùsas do fracasso dessas duas tentativas de planejamento foram as seguintes: a) descontinuidade administrativa; b) falta de um órgão central de planejamento; c) sistema falho de elaboração de projetos apenas parciais para solicitação de verbas em cada exercício, quase sempre abandonados ou não terminados posteriormente; d) votação ou elaboração do orçamento de investimentos com o orçamento de custeio.

Apesar do govêrno que findou em 1945 ter estabelecido algumas regras básicas de uma politica de investimentos, o saldo positivo nesse setor foi quase nulo, principalmente se levarmos Mundial.

No periodo de 1939 a 1945 os investimentos foram pequenos da agricultura e criação de indústrias básicas, tantas vêzes refe. ridas nos projetos do govêrno.

Nos dois anos que antecederam aos anos críticos da guêrra nadu foi feito para a ligação ferroviária Norte-Sul do País, dando como conseqüência a paralisação do comércio interno. Em compensar,ão, gastaram-se somas fabulosas para alojar repartições públicas na antiga Capital Federal, construindo Palácios e outras obras suntuárias.

Francisco das Chagas Melo - Professor da Faculdade de Ciências Contábeis e Administrativas (I.B.C.). 